\title{
Habitat isolation and ecological barriers - the effect on small mammal populations and communities
}

\author{
Michał KOZAKIEWICZ
}

Kozakiewicz M. 1993. Habilat isolation and ecological barriers - the effect on small mammal populations and communities. Acta theriol. 38: 1 - 30 .

Various effects of habitat isolation on both population and community processes in small mammals are presented and discussed; numerous examples are given. Both ecological characteristics of a single patch populations (local population level) and ecological processes among habitat patches (metapopulation level) are presented. The connectivity as a parameter which measures inter-patch processes is discussed. The role of habitat barriers as "filters" structuring both populations and communities of small mammals in heterogeneous environments is presented. It is suggested that ecological processes, which are going on among patchily distributed local populations, make the metapopulation a dynamic, functional unit. Movements of individuals between habitat patches are critical to support the existence of species in a patchy, heterogeneous landscapes. For each species the temporal distribution of activity in space reflects the interactions between the temporal dynamics of the species needs and spatio-temporal dynamics of resources. "Key habitats" play a crucial role for population existence in the dynamics of species' needs and resource supply. The increased mobility of individuals seems to be the best strategy for survival in heterogeneous landscapes. The effect of habitat isolation on genetic divergence within a metapopulation is discussed. It is suggested that the small size of discrete local populations, which temporarily go through a genetic "bottleneck" effect, and occasional migration of individuals between local populations can induce increased, long term genetic variability of the whole metapopulation. It is suggested that landscape heterogeneity and habitat fragmentation affecting the distribution of many species, can also affect interspecific interactions.

Warsaw University, Institute of Zoology, Department of Ecology, Krakowskie Przedmiescie 26/28, 00-927 Warsaw, Poland

Key words: habitat isolation, habitat barriers, metapopulation, small mammals, strategies for survival, heterogeneous landscape, interspecific interactions

1. Introduction

2. Effect of habitat isolation on small mammal populations

2.1. Ecological processes within habitat patches 5

2.1.1. Social and spatial structure of patch populations 6

$\begin{array}{ll}\text { 2.1.2. Demography of patch populations } & 6\end{array}$

2.2. Eoological processes among habitat patches 8

2.2.1. Connectivity 8

2.2.2. Habitat barriers and movements of individuals $\quad 11$

2.2.3. Variability of habitat patches $\quad 16$

2.3. Genetic divergence within metapopulation $\quad 16$

3. Strategies for survival in heterogeneous landscapes $\quad 19$ 
4. Effect of habitat isolation on selected interspecific interactions 22

4.1. Habitat barriers and distribution of species

4.2. Host-parasite interactions. An example: intestinal helminths in Bank vole

5. Summary and conclusions

\section{Introduction}

Early models of population dynamics assumed that species' resources are homogeneous in space. More recent models, however, obviously note the existence of spatial heterogeneity of habitats (Fahrig and Merriam 1985, Lefkovitch and Fahrig 1985, Verboom et al. 1991, Verboom and Lankester 1991). It is because over the last two decades ecologists have turned their attention toward the role played by spatial heterogeneity. Wiens (1976) was one of the first authors to point out this problem very strongly. Recently, spatial heterogeneity is considered as one of the basic factors influencing both population and community processes, especially in man-dominated landscapes (Kozakiewicz 1983). Thus, it is more often explicity included as an important factor in the design of ecological studies.

Spatial heterogeneity of landscapes is mostly affected by fragmentation of previously large habitats into a small, discrete patches. It is caused mainly by human activities (and some natural disturbances), especially in intensively used agricultural landscapes (Merriam 1988, Opdam 1988, and others). Forest fragmentation is the process on which ecologists have focused especially their attention (Burgess and Sharpe 1981, Harris 1984, Kozakiewicz and Szacki 1987, Saunders et al. 1987, Wiens 1989, Gliwicz 1990, and others).

Fragmentation of a large area causes a complex of deep and serious changes in the whole landscape (Forman and Godron 1986). Firstly, the overall area of a habitat being fragmented is reduced, the isolation of habitat patches increases as well as the amount of edge habitats relative to the interior. The native vegetation, extensively removed, remains only in fragmented patches across the landscape.

These spatial effects can lead to the secondary changes, i.e. to the responses of populations and communities. As a result of habitat fragmentation, decrease in species richness is likely to be observed, due to the reduction of a total area of suitable habitats, decrease of remnants' size and increase of their isolation from one another (for review see Saunders et al. 1991). Additionally, the great proportion of edge zone in the whole area of habitat patches can affect changes in species composition. Thus, an increase can be expected in the proportion of ecotone (edge) species as well as species from adjacent habitats visiting remnants (Forman 1981, Janzen 1983, Blake and Karr 1984, Kozakiewicz and Szacki 1987, and others).

Therefore, the situation of remnant patches across the landscape, their size, shape and degree of isolation seem to be very important for landscape management and conservation practice. Changes resulting from the fragmentation and isolation of habitats have been the subject of a considerable debate several years ago, based 
mostly on the equilibrium theory of island biogeography (MacArthur and Wilson 1963, 1967) and its applicability to conservation practice. The basic question was whether one large reserve could preserve more species than several small reserves of equivalent total area (so-called SLOSS debate, i.e. "Single Large or Several Small”). The very high intensity of this debate itself and also many comments around it showed the importance of problems discussed (Diamond 1976, Simberloff 1976, Simberloff and Abele 1976a, b, Terborgh 1976, Whitcomb et al. 1976).

While of theoretical interest, the debate, however, did not solve any practical problems and especially did not answer the question of how to manage fragmented systems (Zimmerman and Bierregaard 1986, Margules and Stein 1989, Saunders et al. 1991). It is because not just species - area relationships are important in evaluating the effects of habitat fragmentation.

Among the huge number of different effects of habitat fragmentation which are discussed in the literature, at least two groups can be distinguished, i.e. changes in the physical environment, and biogeographic changes (Saunders et al. 1991). Considering effects of fragmentation on different levels of ecological integrity changes on ecosystem level and changes on population level can be distinguished as well (Kozakiewicz and Szacki 1987).

Effects on ecosystems contain both physical (e.g. nutrient and water flux) and biological (e.g. species diversity and abundance) changes. Cutting up ecosystems into smaller and smaller parts leads to deep changes in their functioning, leading to the so-called "minimum critical ecosystem size" (Lovejoy and Oren 1981). Changes are manifested by losses of distinct character and autonomy of remnants - the contribution of species visiting from surrounding areas increases as well as the proportion of matter and energy transported across their boundaries. The instability of remnants increases, according to the changes in surrounding areas (Kozakiewicz and Szacki 1987). Patches of different degrees of autonomy and different stability can, therefore, form a "dynamic mosaic" offering a huge diversity of living conditions for populations across the fragmented landscape.

Spatial distribution of many animal species can be strongly affected by habitat fragmentation. Occurrence of many species may be limited to the patches of habitat more or less suitable for their settlement, surrounded by unhabitable or poorer areas. These intervening areas may act as barriers which, to various degrees, may impede the dispersal of individuals across them. According to Levins (1970), a group of semi-isolated small local populations inhabiting patches of suitable habitat may act as a single ecological unit - "metapopulation", defined as “...population of populations which go extinct locally and recolonize...". In Levins' (1970) concept of metapopulation there is no stable, large population (continuous distribution), but only small, unstable local (patch) populations (non-continuous distribution) which can go extinct because of their small size. The dynamic demographic equilibrium of the whole metapopulation is supported by occasional migration of individuals between patches and recolonization processes. The whole of Levins' (1970) metapopulation is thus spatially and functionally structured as 


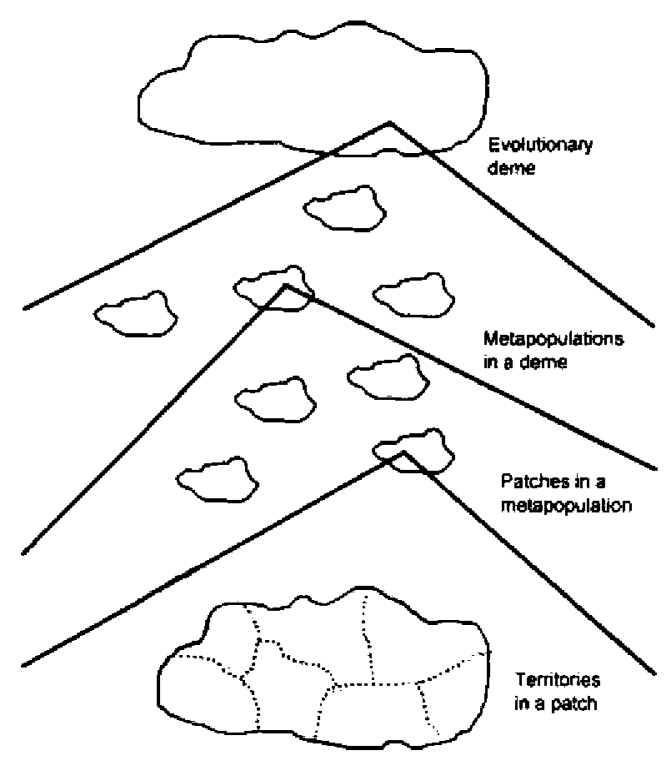

Fig. 1. Spatial hierarchy representing patchy metapopulations. After Merriam (1988).

a demographic unit existing in a fragmented, heterogeneous environment, which is changeable in space and time.

Contrary to Levins' (1970) concept, the metapopulation model described by Boorman and Levitt (1973) assumes the existence of one large and stable population which acts as a reservoir of individuals dispersing from there and temporarily colonizing habitat patches surrounding it. Despite the differences between them, the crucial processes described in both metapopulation concepts mentioned above, are the same: local extinctions and recolonizations. The functioning of the whole metapopulation is supported by dispersal of individuals among patches of habitat (which can differ from one another in respect to their stability and quality) in a heterogeneous, fragmented landscape.

Since metapopulation terminology is not used by ecologists in a consistent manner, I find it useful here to explain that in the present paper I follow metapopulation terminology proposed by Hanski and Gilpin (1991): (1) patch "the area of space within a local population lives", (2) local population (= patch population) - "set of individuals which all interact with each other with a high probability." Local populations can go extinct frequently because of their small size, (3) turnover - "extinction of local populations and establishment of new populations in empty habitat patches by dispersers from existing local populations", (4) metapopulation - "set of local populations whitch interact via individuals moving among populations". According to Hanski and Gilpin (1991) there is a conceptual distinction between three spatial scales referring to different structures and processes: (1) local scale - "the scale at which individuals move and interact with each other in a course of their routine feeding and breeding activities", (2) metapopulation scale - "the scale at which individuals infrequently 
move from one place (population) to another, typically across habitat types which are not suitable for their feeding and breeding activities, and often with substancial risk of failing to locate another suitable habitat patch in which to settle, (3) geographical scale - "the scale of species' entire geographical range; individuals have typically no possibility of moving to most parts of the rangen.

According to Merriam (1988), there is a hierarchy of spatial and temporal scales within patchy metapopulations. The spatial and tempotal hierarchy includes: (1) level of individual territories, (2) level of movement range of dispersers, (3) level of geography of metapopulations, corridors and barriers, (4) level of geography of demes, gene flow and barriers at that scale, (5) level of the time and space relations of evolution. Temporal scales in this hierarchy slow with increasing spatial scale from hourly to evolutionary (Merriam 1988) (Fig. 1).

The aim of the present paper is to present and discuss different effects of habitat fragmentation on small mammal populations (based partly on my own data). The effects of habitat fragmentation are presented and discussed at the level of processes both within and between local habitat patches, with some connections to the metapopulation level. The effects of habitat fragmentation on some selected interspecific interactions are also presented and discussed.

\section{Effect of habitat isolation on small mammal populations}

\subsection{Ecological processes within habitat patches}

Levins' (1970) metapopulations are functionally structured as demographic units thus, when discussing population demography in fragmented landscapes, dynamics of a whole metapopulations should be considered. The dynamics of each metapopulation are built up as a result of within-patch demographic processes and between-patch movements of individuals.

There are three major possible effects of within patch population processes on metapopulation dynamics. Firstly - metapopulation dynamics are directly affected by changes in the natality/mortality balance of each patch population. Demographic processes in patch populations drive the dynamics of the whole metapopulation by causing local fluctuations in numbers and, sometimes, extinctions of local populations (quantitative effect).

The second possible effect is internal differentiation within metapopulation (qualitative effect). Patch populations are not all the same, but they can differ distinctly from each other with respect to their ecological structure (for example sex or age structure) according to the quality of habitat patches being occupied and within patch population ecological processes. The problem of importance of patch differentiation within metapopulation will be discussed later in this paper.

The third effect of within patch population processes on metapopulation demography is interpatch dispersal of individuals (both qualitative and quantitative effects). The intensity of inter-patch dispersal and also the characteristics of 
dispersing individuals can be strongly affected by within patch ecological processes. The problem of importance of interpatch dispersal of individuals for the functioning of metapopulations will be discussed later in this paper.

\subsubsection{Social and spatial structure of patch populationg}

The relationships between mean home range size and population numbers in large populations (inhabiting a continuous forest) and local (patch) populations of bank voles have been studied by Kozakiewicz (1985). The studies were carried out simultaneously on two study areas separated from each other by a distance of about $3 \mathrm{~km}$ in a stright line. The first area was $2.28 \mathrm{ha}$ in extent and situated inside a large forest area of about 3000 ha. The second area ( 2.43 ha in extent) consisted of a small isolated patch of wooded land. CMR method was used. In
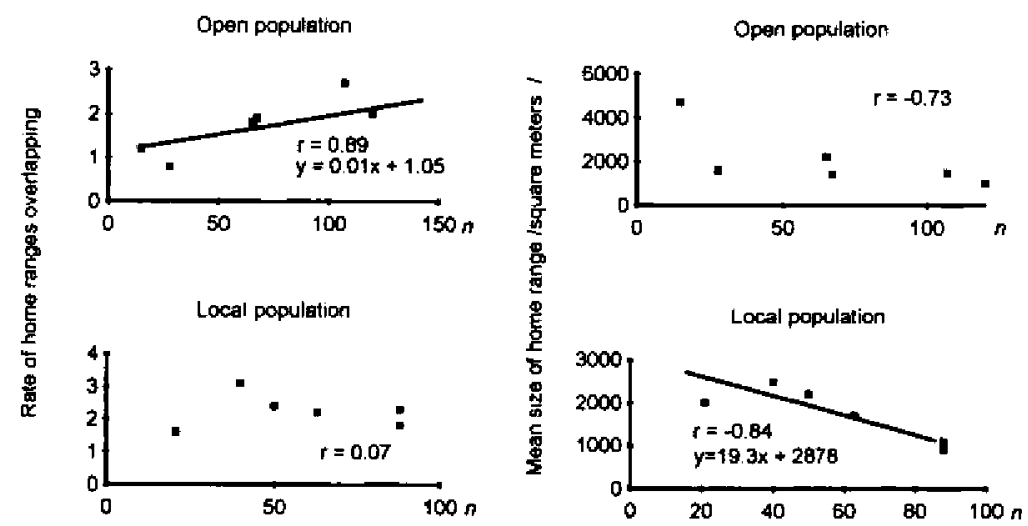

Fig. 2. Relation bet veen population size $(n)$ and degrees of overlapping of home ranges and mean size of home range in the large (open) and patch (local) populations of Bank voles Clethrionomys glareolus. After Kozakjewicz (1985), modified.

patch populations the mean size of individual home ranges exhibited a distinct, negative correlation with population numbers. Increase in population numbers did not affect, therefore, the increase in overlapping of individual home ranges (Fig. 2). The same has not been found in large forest population. It was, therefore, concluded that in patch populations more intensive antagonistic interactions take place among individuals. Such interactions may result in low mutual tolerance of individuals in the overlapping parts of their home ranges. Thus, with increase in population density and limited space, decrease in the size of home ranges takes place limiting home range overlap and, in consequence, limiting direct contacts among individuals. This mechanism may also reduce density-dependent emigration of individuals from patch populations.

\subsubsection{Demography of patch populations}

Population dynamics, that is, changes in the number of individuals with time, is the outcome of: birth rate, death rate, emigration and immigration. 
Population dynamics and turn-over of individuals in patch population of Bank volies Clethrionomys glareolus inhabiting isolated woodlot, compared to a large, continuous forest population, has been studied in detail by already quoted Kozakiewicz (1985). Distinct limitation of reproduction was found in the patch population compared to a large forest. It was caused by the limited number of reproducing females. It was suggested that the limitation of reproduction in patch Bank vole populations is the consequence of the specific social and spatial organization of the population, similar to that described for island populations by Bujalska $(1970,1973)$ and Gliwicz (1980). I consider this as due to the limited area of the island (habitat patch) capable of "accomodating" a certain number of home ranges of strongly territorial adult females.

Table 1. Seasonal changes in the litter size (number of embryos \pm SD) of the Bank voles Clethrionomys glareolus in patch and open populations. * - numbers of females investigated are given in parentheses.

\begin{tabular}{lccc}
\hline \multirow{2}{*}{ Month } & $\begin{array}{c}\text { Patch population } \\
\text { Poland }\end{array}$ & \multicolumn{2}{c}{ Open population } \\
\cline { 3 - 4 } & \multicolumn{2}{c}{ Poland } & Czechoslovakia (Zejda 1966) \\
\hline May & $4.8 \pm 1.1(10)^{*}$ & $4.9 \pm 1.0(22)$ & $5.2 \pm 0.1(147)$ \\
June, July & $6.2 \pm 1.0(19)$ & $5.6 \pm 0.8(45)$ & $4.7 \pm 0.2(42)$ \\
September & $4.8 \pm 1.9(16)$ & $4.7 \pm 1.1(21)$ & $4.4 \pm 0.2(20)$ \\
\hline
\end{tabular}

Comparison of mean litter size and its seasonal changes in patches and large, continuous Bank vole populations shows no significant differences (Table 1). That is, the changes in mean litter size cannot be taken as an other possible mechanism reducing natality in patch Bank vole populations.

Contrary to reduced natality, a relatively high survival rate of bank voles in a patch population has been found compared to a large forest population (Kozakiewicz 1985). The differences were especially visible in the winter survival of animals: 33\% of individuals present in autumn in the patch population had survived winter, while in large forest population it had been as low as only $4 \%$ of individuals. High survival rate of individuals was probably one of the reasons for the relatively low turn-over rate in patch population. Consequently, the mean period of stay of an individual in the large forest population was only 135 days compared to 167 days in the patch population of Bank voles (Kozakiewicz 1985).

Besides the natality and mortality of individuals, the possibility to disperse between habitat patches might constitute one of the ways of controlling the numbers in patch populations. Kozakiewicz (1985) and also Kozakiewicz and Szacki (1987) postulated that, in certain cases, in local patch populations emigration rates can greatly exceed immigration rates and, in consequence, cause the reduction in their density. In distinctly isolated patch populations, however, emigration of individuals may be strongly limited (Szacki 1987). 


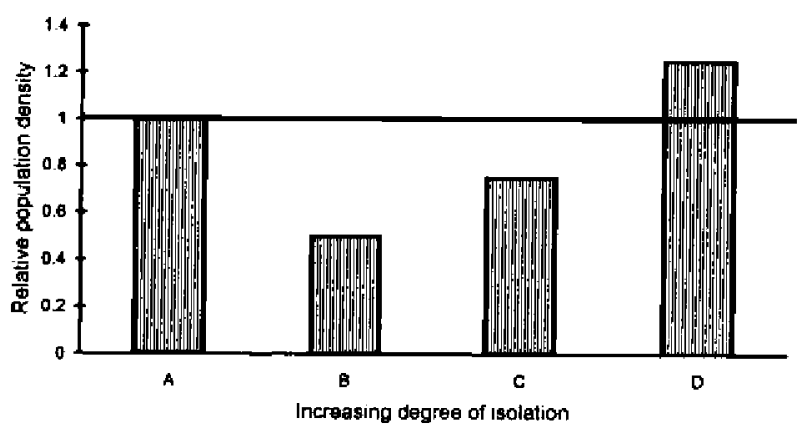

Fig. 3. Relative density of the Bank vole Clethrionomys glareolus population varying in the degree of isolation in relation to large, continuoug population density. A - large population (density assumed as equal 1), B - a population connected with a large one by an ecological corridor, C, D - populationg occupying habitat patches of an increasing degree of isolation (D more isolated than $\mathrm{C}$ ). Afler Kozakiewicz and Szacki (1987).

According to Kozakiewicz and Szacki (1987), the density of Bank vole patch populations depends on the degree of their isolation (Fig. 3). If density in large (continuous) populations is assumed as equal to 1 , in relation to this, densities of patch populations are expected to be less than 1 (for less isolated populations) or more than 1 (for strongly isolated populations). In the literature there are some papers describing higher densities of patch populations of small mammals compared to large ones (e.g. Smith and Vrieze 1979, Szacki 1987), and some describing lower densities for them (e.g. Stickel and Warbach 1960, Windberg and Keith 1978, Gottfried 1979, 1982, Kozakiewicz 1985).

Thus, the relatively high density of strongly isolated patch populations (caused probably by low emigration rates) as well as good survival of individuals (especially during the winter) seem to be possible mechanisms reducing the probability of extinctions of a local patch population. It is not fully consistent with many authors suggesting stochastic, patch size-and isolation effects as only factors influencing directly the probability of extinction of patch populations.

It also can be concluded that internal social and spatial organization of patch populations can affect intensity of inter-patch dispersal and, in consequence, the probability of recolonization of a new, empty patches of habitat.

2.2. Ecological processes among habitat patches

\subsubsection{Connectivity}

Many authors draw attention to the important role played by dispersal in animal populations. In mosaic environments, dispersal of organisms among habitat patches can influence the demographic properties and stability of each patch population as well as the dynamics of the whole mosais system (den Boer 1968, Reddingius and den Boer 1970, Roff 1974a, b, 1975, and others). In both Levins' (1970) and Boorman and Levitt's (1973) concepts of metapopulation dispersal of individuals and recolonization of empty habitat patches are considered to be crucial processes maintaining the existence of metapopulations in a long time. 
According to Merriam (1991), there are three major demographic effects from interpatch dispersal. Firstly, interpatch movements enhances metapopulation survival. Secondary, interpatch dispersal supplements population growth during the limited breeding season between severe winters. The third effect of interpatch dispersal is recolonization once local extinctions has taken place.

Populations of White-footed mice Peromyscus leucopus and Eastern chipmunks Tamias striatus have been studied in detail by Merriam and coworkers in farmland mosaic near Ottawa, Canada (Wegner and Merriam 1979, Middleton and Merriam 1981, 1983, Henderson et al. 1985). It has been shown that patch populations of small mammals can frequently go extinct, especially in spring - the time of a deep population decline. For example, Henderson et al. (1985) recorded local extinctions in almost one third of habitat patches being studied. These local extinctions were recolonized during spring by individuals dispersing from other, source populations.

Results of these papers confirmed fully Levins' (1970) concept of metapopulation and indicated that frequent extinctions of local populations can take place in woody patches in farmland mosaic. Recolonization is thus really critical for supporting the continuous existence of the species in the landscape. Recolonization of empty habitat patches may depend upon interconnection of landscape elements (i.e. distance from the nearest source population, presence of habitat barriers and/or corridors between habitat patches) and may depend also on the mobility of dispersing animals (colonists).

Based on these statements, Merriam (1984) has introduced the concept of "connectivity", defined by him as: "...a parameter which measures the processes by which the subpopulations of a landscape are interconnected into a demographic functional unit...". According to this definition, the connectivity is behaviourally determined, species-specific parameter which depends both on the landscape composition and on the certain aspects of the movement patterns of the animals (Hansson 1988).

It can be expected that an increase in connectivity of a mosaic would decrease the frequency of local extinctions. This assumption has been tested and confirmed with a mathematical model and field data (Fahrig and Merriam 1985, Lefkovitch and Fahrig 1985). Survival rates of individuals in four patchily distributed local populations of white-footed mice were simulated in different degrees of connectivity between patches. It was found that the probability of population survival is higher in connected patches than in isolated ones. The effect was measured by the number of years until local extinctions (Fig. 4), and was checked by field data.

The concept of connectivity, concerning a very fundamental ecological processes in a mosaic environment, seems to be of high importance both for landscape ecology theory and landscape management practice. It provokes also some basic questions and problems. Firstly, the question of distances and routes traversed by different animal species arises. How far can animals travel and what barriers are they able to cross? Answering this question seems to be necessary when problems of 


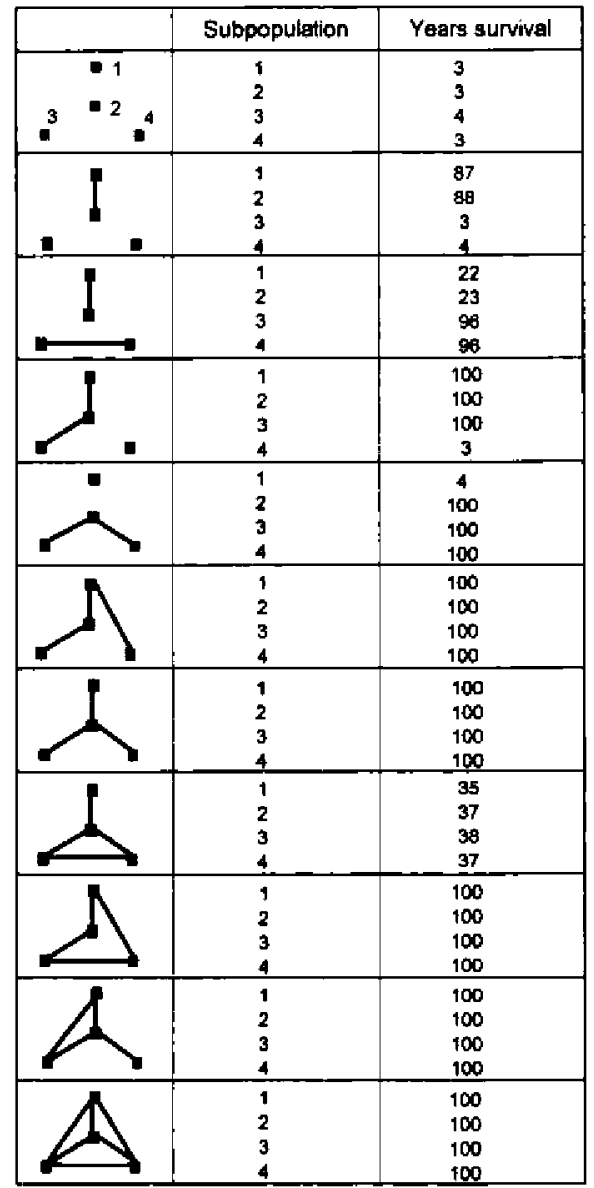

Fig. 4. Simulated years of survival of 4 patch populations $(1,2,3,4)$ of White-footed mouse Peromyscus leucopus for different degrees of connectivity. After Merriam (1984), modified.

metapopulation boundaries are discussed (HOW FAR IS FAR ENOUGH to put boundaries on metapopulation?), and also - when problems of metapopulation functioning and spatial management of landscapes are discussed (HOW FAR IS NOT TOO FAR to keep the existence of metapopulation?).

The second problem arising from the concept of connectivity is the problem of ecological mechanisms releasing inter-patch dispersal, and also the problem of inter-patch dispersal dynamics.

The third question provoked by the connectivity concept concerns ecological characteristics of dispersing individuals, as potential founders of new patch populations. Do inter-patch dispersers differ distinctly from non-dispersers in certain aspects? If so - what is their ecological characteristic and how can it influence their success as founders of new patch populations?

The fourth question concerns certain aspects of the movement patterns of the animals. Are the boundaries of habitat patches really sharp for all animals inhabiting them? Are contacts between patches possible only by dispersing 
individuals? Isn't it possible for certain individuals to cross periodically the surrounding habitats, visit neighbouring habitat patch and go back to the "home" patch again? Finally, is it possible (for certain species) to use different elements of a habitat mosaic and travel between them periodically?

\subsubsection{Habitat barriers and movements of individuals}

Wolton and Flowerdew (1985) distinguished three types of spatial activity of small mammals: (1) movements within individual home ranges, (2) short-term, return movements of individuals outside their home ranges (so-called "exploratory excursions"), (3) dispersal movements. For recent review of dispersal patterns in small mammals see Stenseth and Lidicker (1992).

Movements within individual home ranges are strongly restricted to the habitats occupied. These movements can be easily stopped by habitat barriers like roads (Oxley et al. 1974, Kozel and Fleharty 1979, Wilkins 1982, Mader 1984, Swihart and Slade 1984, Bakowski and Kozakiewicz 1988, Merriam et al. 1989) or powerline corridors (Schreiber and Graves 1977). These barriers are not absolute barriers, but can be effective inhibitors of movements, acting at the level of individual home ranges. Bakowski and Kozakiewicz (1988) have found that a $5 \mathrm{~m}$ wide forest road acts as a quantitative (but not qualitative barrier on Bank vole movements. Movements of voles across the road were very infrequent, but almost all individuals translocated across the road returned back to their original side. It was therefore suggested that it is a behavioural choice of the voles, but not absolute impossibility, which prevents individuals from crossing the road. A similar barrier effect has not been found for Yellow-necked mouse Apodemus

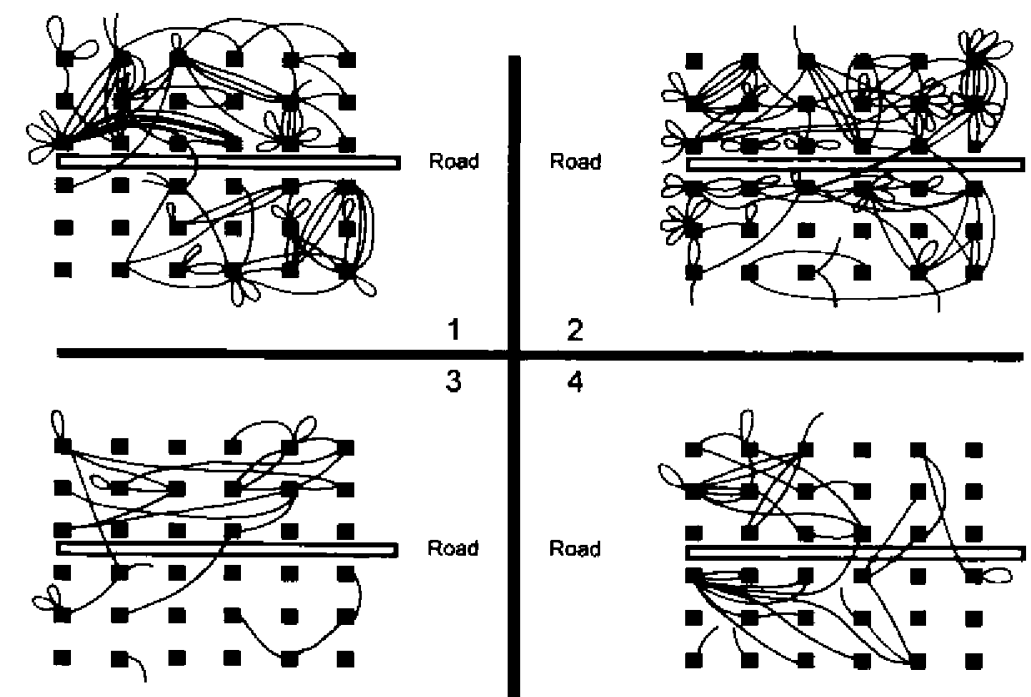

Fig. 5. Movements of White-footed mice Peromyscus leucopus within forest bisected by roads and across the roads 1, 2, 3, 4 - study areas, black squares - trapping points. After Merriam et al. (1989). 
flavicollis. Also Merriam et al. (1989) have described a similar barrier effect of a narrow, gravel road on movements of White-footed mice. On four study areas movements of White-footed mice were very infrequent - only 9 from among 115 marked individuals crossed the roads $(7.9 \%)$. However, the frequency and extent of movements between the traps not separated by the road were frequent and mice moved distances that were long enough to cross the road (Fig. 5).

At the demographic level all these roads were not effective barriers for stopping recolonization of empty habitats, they also were not effective barriers to gene flow, but were effective enough to inhibit movements of individual Bank voles and White-footed mice.

Similar effects (i.e. inhibition of movements on the level of single individuals) can be caused by social interactions among individuals. Behavioural barriers inhibiting movements of individuals, created by the presence of individuals of other species have been described by Merriam (1990) and Dobrowolski et al. (in press).

Movements of individuals outside their home ranges seem to be more important for the levels of metapopulation demography and genetics. In recent literature there are some data indicating unexpectadly long distances crossed in short time periods by small mammals (Andrzejewski and Babińska-Werka 1986, Liro and Szacki 1987, Wegner and Merriam 1990). There is also some evidence indicating that distances crossed by animals are longer in heterogeneous habitats compared to homogeneous ones (Kozakiewicz et al., in press).

The range of movements of Bank vole individuals and width of barriers they are able to cross, have been studied in detail. Bank voles were removed from their original places in a forest and translocated different distances across a habitat barrier (ploughed field). Per cent of individuals returning to their original places decreased when barrier width was increased (Fig. 6). Linear regression estimated the theoretical maximum distance which animals are able to cross as about 750 $\mathrm{m}$ for females and about $850 \mathrm{~m}$ for males.

A relatively high percentage of returning individuals, even from very distant release points, provokes the question of how the animals find the way back. It

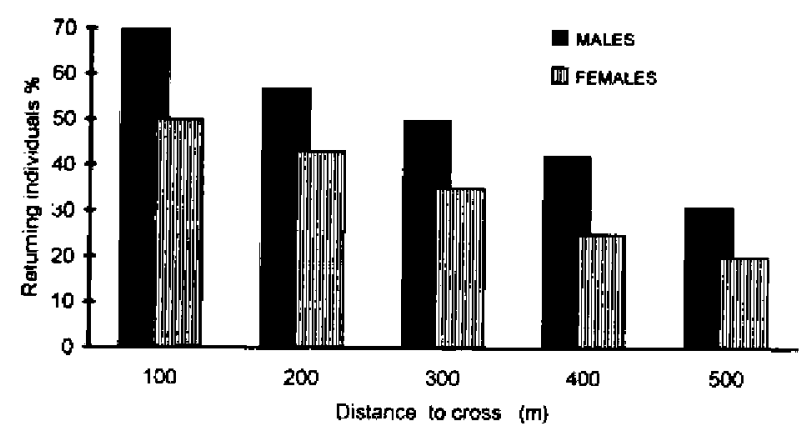

Fig. 6. The percentage of Bank vole, Clethrionomys glareolus individuals returning back to their home places from groups of individuals translocated different distances across a habitat barrier. 
seems possible that some of the animals were already familiar with the vicinity of their release points. It can be hypothesized that many small mammal species (including Bank voles) do not have a sharply defined range boundaries, limited by the boundaries of habitat patches they occupy. It is possible that they visit surrounding areas infrequently and return to the occupied habitat patches. Some data suggest that such exploratory excursions commonly occur (Wolton and Flowerdew 1985). Thus, some animals released even far from their original places, could already be well experienced in finding their way back. Results presented here show males to be better "between-patch" explorers, since they travel longer distances than females (Fig. 6).

If exploratory excursions of individuals inhabiting habitat patches really occur commonly, the picture of a metapopulation as a group of local populations which are patchily distributed and limited to the area of occupied habitat patches, connected only by occassional movements of animals between them, should be re-built. The area of a high frequency of movements of animals (the area of the habitat patch) may be, at least in some seasons, surrounded by a zone of lower frequency exploratory movements, connecting and integrating neighbouring patch populations (Fig. 7). Some data concerning the use of spatial elements of the landscape by White-footed mice (Wegner and Merriam 1990) and also Wood mice and Bank voles (Bauchau and Le Boulengé 1991) seem to be fully consistent with this hypothesis. Even at low frequency, exploratory movements of animals can be

Fig. ". Metepopulation. Dark spots - patches of habitat presently occupied, white spots - patches of habitat not occupied at present. Arrows show possible directions of animals' movements, shaded areas - terrains explored by animals from habitat patches.

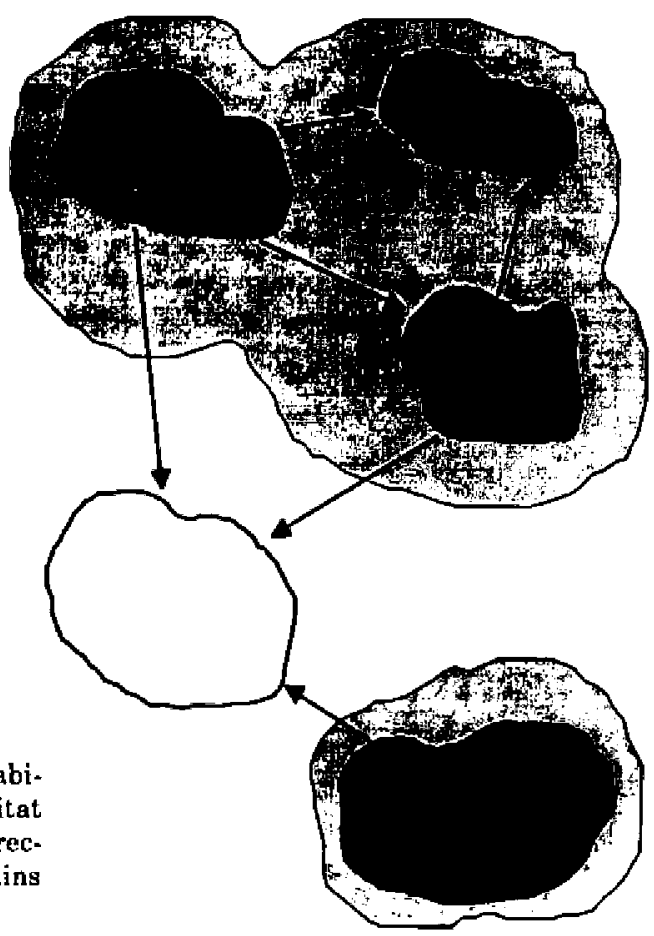


very important for gene flow between patch populations in a longer time, if we assume that exploring individuals can mate outside their "home" patches.

Dispersal may have a strong influence on gene flow and population demography; it may aid colonization and persistence of local patch populations, promote population stability over large areas and be involved in regulation of population numbers (Wolton and Flowerdew 1985). Inter-patch dispersal movements of small mammals have been already studied by Hansson (1977a, b, 1981, 1987), Wegner and Merriam (1979), Middleton and Merriam (1981, 1983), Henderson et al. (1985), Gliwicz (1989), Kozakiewicz and Jurasińska (1989), van Apeldoorn et al. (1992), and many others.

As postulated by Hansson (1988), in order to have a rapid recolonization of patches with a temporarily extinct subpopulation, dispersal should occur at or just before the reproduction period and it should include a remarkable proportion of reproductive (pregnant) females. Descriptions of inter-patch dispersers generally do not confirm Hansson's (1988) postulates, although there is some evidence indicating distinct character of dispersing individuals.

Kozakiewicz and Jurasińska (1989) simulated a local extinction by removal of all small mammals from a small woodlot surrounded by meadows. The experiment

Table 2. Comparison of mean body weight \pm SD (g) of Bank vole Clethrionomys glareolus individuals recolonizing depopulated woodlot and a vacant area inside a large forest. $n$ - number of individuals. After Kozakiewicz and Jurasińska (1989), modified.

\begin{tabular}{lcc}
\hline Trapping area & Males & Females \\
\hline Forest & $19.1 \pm 4.5$ & $18.4 \pm 4.1$ \\
& $n=29$ & $n=14$ \\
Woodlot & $17.4 \pm 3.3$ & $16.0 \pm 2.2$ \\
& $n=25$ & $n=17$ \\
\hline
\end{tabular}
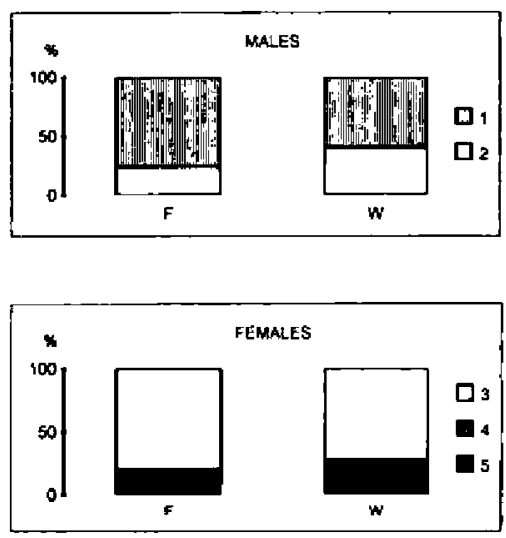

Fig. 8. Percentages of sexually active Bank voles Clethrionomys glareolus in groups of dispersers recolonizing empty woodlot (W) and control depopulated gap in a large forest settlement (F). 1 - males sexually inactive, 2 males sexually active, 3 - females sexually inactive, 4 pregnant and lactating females, 5 - Cemales sexually active but not reproducing. After Kozakiewicz and Jurasinska (1989), modified. 
was carried out in two separate 1.35 ha study areas. The first experimental area ("Woodlot") consisted of a small patch of wooded land surrounded and separated by meadows. The second experimental area ("Forest") was a plot within a large (about 3000 ha) continuous forest. CMR method was used. During the three days following the first trapping period, all previously marked small mammals caught both in "Woodlot" and "Forest" sites were removed. Individuals entering and recolonizing these two experimental plots in $2 \mathrm{nd}$, 4 th and 7 th week after removal were compared. Individuals involved in the immigration and recolonization of the depopulated woodlot were distinctive. A higher percentage of sexually active animals, but lack of reproducing females and also slightly lighter body weights have been found in the group of Bank voles recolonizing the depopulated habitat patch, compared to the animals recolonizing a depopulated area inside a large forest (Fig. 8, Table 2).

Detailed description of dispersal dynamics of both different age and sex categories of Bank voles and Wood mice is given recently by Gliwicz (1992). Despite the seasonal differences dispersal in voles and mice appears to be more common in males than in females and in young age classes rather than in adult individuals. However, the proportion of juveniles (individuals of age below 1.5 month) in the group of inter-patch dispersers of Bank voles is much higher than in the control group dispersing into a vacant area inside a large forest. The differences continue during the whole reproductive season (May - October) (Fig. 9).

It might, therefore, be suggested that the habitat barriers can act as a "filters" which stop some individuals and allow other to pass through. Such "filters" can play an important role in structuring small populations isolated by habitat (Kozakiewicz and Jurasińska 1989). "Filtering out" of different individuals by habitat barriers cannot be, however, understood as a simple function of a certain environmental features (e.g. barrier width). This process depends not only on the landscape composition, but also on abilities of different categories of individuals to move across the barriers. Therefore, it should be considered rather as an individual-specific process, which depends also on multiple characteristics of habitat barriers.

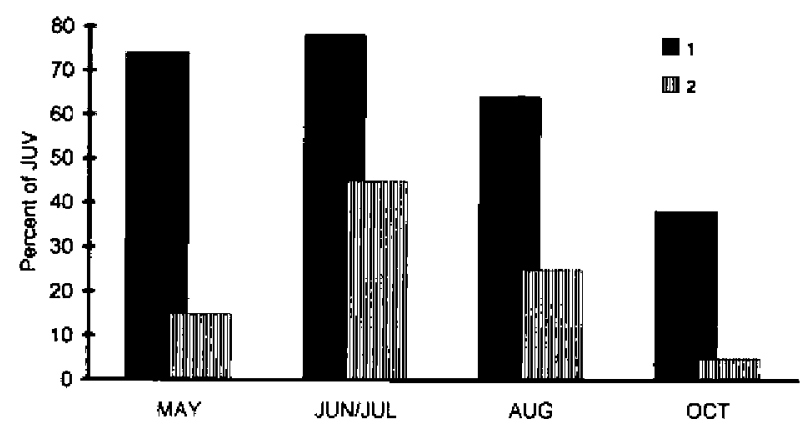

Fig. 9. Seasonal dynamics of the percentage of juveniles among inter-patch (1) and inside-forest (2) dispersers. 


\subsubsection{Variability of habitat patches}

Spatial heterogeneity of landscapes - differences in quality of habitat patches and their different positions across the landscape - may affect the distribution of species and persistence of populations. Den Boer (1968) demonstrated with a stochastic mathematical model that in heterogeneous and variable environments the chance of population survival may be increased. It is because the variation within a metapopulation makes it possible to cope with variation in space and time of the habitat. According to den Boer (1968), the risk of the extinction of the whole metapopulation can be spread throughout a heterogeneous space, because the chances of local population survival are different in different patches of habitat (so-called "spreading of the risk" concept). Den Boer maintains that: "...the fluctuations of animal numbers in the population as a whole will be a resultant of the numerical fluctuations in the different places (subpopulations)...Migration between subpopulations will generally contribute to the stabilizing tendency of spatial heterogeneity, since in this way extreme effects of some places will be levelled out more thoroughly. Hence, migration will improve the outcome of spreading of the risk in space..."

A mosaic of habitats of different quality across the landscape creates for animal populations opportunities to select them, according to the requirements of the species. Hansson (1977a, b) has deseribed habitat selection by Field voles Microtus agrestis in heterogenous landscapes. With regard to a year-round changeability of habitats, Hansson (1977a) has distinguished, for Field voles, permanent habitats (suitable year round) and temporary habitats. With regard to population size, the high density habitats, low density habitats and vole-free habitats have been distinguished as well. An increase in density in certain habitats may cause a dispersal of animals looking for new places to establish residence. Dispersal can be widespread across the landscape according to the "stepping stone" model and affect the colonization of new habitat patches. Accordir to Hansson (1977a), dispersal is most probable from weaned juveniles, thus inuividuals colonizing new habitat patches - especially in spring time - are expected to be mainly weaned juveniles.

A quite similar processes of dispersal of weaned juveniles searching for new empty habitat patches to occupy, has been described for Bank voles by Gliwicz (1989). Young individuals, after establishing their residence in empty suboptimal patches of habitat, have a high probability of maturing and reproducing in the year of their birth. Later in the season all patches become "saturated" and there is no place for dispersers to establish a new residence.

\subsection{Genetic divergence within metapopulation}

Movements of individuals between habitat patches have been discussed above in terms of metapopulation dynamics (recolonization of empty patches vs extinction processes). This raises, however, questions about gene flow across the landscapes and genetic variability within the metapopulations. Besides the obvious impli- 
cations for conservation, especially of endangered species, these questions raise also important issues in population biology.

If the animals are patchily distributed, gene flow between local populations is partly restricted, according to the degree of isolation of local populations. It prevents random breeding, but does not cause genetic isolation of each subpopulation. Some authors discuss the effects of inbreeding and genetic drift in fragmented populations and postulate that metapopulation structure can increase inbreeding (i.e. Gilpin 1987). It seems, however, that opposite to Gilpin's (1987) opinion, there are no field data which can confirm this statement.

However, if patch populations frequently go extinct and recolonize, each patch population will have gone through a genetic bottleneck effect during the recolonization period. The same effect can be observed in small mammal populations showing a deep spring decline in density. A few individuals which start to breed in spring can act as founders for later population growth (Bauchau and Le Boulengé 1991, Saunders et al. 1991). Such bottleneck effects in small mammal populations have been described by Corbet (1963), Sikorski (1982), Sikorski and Bernshtein (1984), Bauchau (1987), Bauchau and Le Boulengé (1991).

According to many authors, the expression of non-metric skull variants is under genetic controll, which makes it possible to use them to assess genetic divergence within and between populations (Markowski and Sikorski 1987, Bauchau 1988). Kozakiewicz and Konopka (1991) studied the frequency of selected non-metric skull variants in open and local Bank vole populations. Bank voles were trapped in three separated sites. The first - "Woodlot" site - was a small ( 1.35 ha) wooded patch surrounded and isolated by meadows. The second ("Forest") and third ("Control") trapping sites were situated inside the large, continuous forest (about $3000 \mathrm{ha}$ ). The distance between the "Woodlot" site and the nearest site in the forest ("Forest" site) was about $300 \mathrm{~m}$ and the same distance separated two forest sites ("Forest" and "Control" ones). The frequency of skull variants was used to evaluate the effect of habitat isolation on genetic structure of Bank vole populations. The MMD (mean measure of divergence) was calculated to estimate genetic differences between groups of animals from different trapping sites. It was found that MMD differences were significant between "Woodlot" and "Forest" and between "Woodlot" and "Control", but not between "Forest" and "Control" (both continuous forest sites (Table 3). The "Woodlot" group of Bank voles (isolated by habitat) differed genetically from both groups of animals inhabiting continuous forest. A bottleneck effect was suggested as a possible cause of the differences. Kozakiewicz and Konopka (1991) collected their materials in spring - the season in which genetic divergence within metapopulation caused by bottlenect effect is most visible and easy to detect. However, later in the season, transfer of individuals between subpopulations may decrease or even remove the bottleneck effect (Boecklen and Bell 1987).

Merriam et al. (1989) have not found genetic differences between White-footed mice subpopulations studied near Ottawa, Canada. The frequencies of three 
Table 3. Mean measure of genetic divergence (MMD) between isolated "Woodlot" (situated inside the large, continuous forest) and non-isolated "Forest" and "Control" groups of Bank voles Clethrionomys glareolus. The dostance between "Woodlot" site and "Forest" site was about $300 \mathrm{~m}$ and the same distance separated "Forest" and "Control" sites. * - MMD values statistically significant. After Kozakiewicz and Konopka (1991), modilied.

\begin{tabular}{lll}
\hline Area & Forest & Woodlot \\
\hline Control & 0.0881 & $0.5596^{*}$ \\
Forest & & $0.4072^{*}$ \\
\hline
\end{tabular}

Table 4. Salivary amylase electromorph frequencies in Whitefooted mouse Peromyscus leucopus from forest fragments isolated from each other by crop fields. After Merriam et al. (1989), modified.

\begin{tabular}{cccc}
\hline \multirow{2}{*}{$\begin{array}{c}\text { Forest } \\
\text { fragment }\end{array}$} & \multicolumn{3}{c}{ Allele frequency } \\
\cline { 2 - 4 } & "Fast" & "Medium" & "Slow" \\
\hline 1 & 0.13 & 0.78 & 0.09 \\
2 & 0.30 & 0.70 & 0.00 \\
3 & 0.14 & 0.82 & 0.04 \\
4 & 0.12 & 0.76 & 0.12 \\
5 & 0.07 & 0.93 & 0.00 \\
6 & 0.21 & 0.79 & 0.00 \\
7 & 0.10 & 0.90 & 0.00 \\
8 & 0.21 & 0.79 & 0.00 \\
9 & 0.25 & 0.64 & 0.11 \\
10 & 0.08 & 0.92 & 0.00 \\
11 & 0.35 & 0.65 & 0.00 \\
\hline
\end{tabular}

electrophoretic variants of salivary amylases were established for mice caught in forest fragments separated from each other by cultivated fields. Data showed that studied subpopulations were genetically very similar (Table 4). Merriam et al. (1989) collected their materials in summer and autumn.

During one reproductive season, genetic divergences between small mammal subpopulations can fluctuate visibly. In spring high mortality of animals, causing a deep decline in densities or even extinctions of several subpopulations, can cause a high genetic divergence between patches within metapopulation. Transfer of individuals between habitat patches can reduce these differences later in the season, making the whole metapopulation genetically more homogeneous.

Although the data are lacking, it is possible to speculate on the possible influence of habitat fragmentation on long-term genetic variability of the whole 
metapopulation. Gilpin (1987) maintains, that if turn-over of subpopulations is frequent, they will derive all of their genetic variation from a few individuals only. Metapopulation as a whole will thus have a very homogeneous structure with low genetic variability. This scenario seems to be possible, but only if the role of connectivity is omitted and subpopulations are assumed to be strongly isolated from each other. This assumption, however, is contradictory to real data on movements of animals.

According to Chepko-Sade et al. (1987), even occasional migration of genes between subpopulations can favour the occurrence of high genetic variability within the whole metapopulation, if losses of alleles of each subpopulation are random. Randomness of gene losses helps in maintaining low rates of the loss of alleles from the metapopulation as a whole (especially if the metapopulation consists of a many subpopulations). It might, therefore, be expected that when a new, adaptive gene combination appears, it can become established by selection in a small subpopulation far more quickly than in a large population by mass selection. Transfer of individuals can quickly introduce this new, favourable genetic combination to other subpopulations.

Thus, the small size of discrete subpopulations and occasional transfer of individuals between them can induce temporal genetic variation within the patches as well as increased genetic variability in the whole metapopulation in the longer term (Chepko-Sade et al. 1987, Kozakiewicz and Konopka 1991).

\section{Strategies for survival in heterogeneous landscapes}

Mosaic landscapes consisting of relatively small and changeable patches of various habitats offer for species living there a multi-partite, wide spatial array of resources. It can be suggested that if all life requirements of each species are fully identified, habitat types within a mosaic could be classified according to their quality as: optimal, suboptimal, marginal or hostile (inhabitable) for a given species. However, the resource availability of each of habitat patches may have a temporal sequence driven by many factors (e.g. plant growth, seasonal climate, influence of surrounding habitats etc.) and species' requirements may also have their own temporal sequence. Thus, for each species, the temporal distribution of activity in space should reflect the interactions between the temporal dynamics of the species' needs and spatio-temporal dynamics of resources to fill these needs.

Since any single small and changeable patch of (temporarily suitable) habitat cannot satisfy all life requirements of a species and cannot support the existence of a stable and viable population, animals must adapt behaviourally to changed spatial and temporal scales by using various resources dissipated in space and changeable in time. Considering behavioural adaptations of small mammals for living in such a patchy and changeable mosaics of habitats, at least two different strategies for survival can be distinguished: (1) the strategy of high spatial activity and (2) the strategy of dormancy ("waiting for better conditions"). 
The first of them and probably the most often realized one is based on active selection of actually best patches of habitat due to actual species' needs and moving abilities of individuals. Numerous groups of dispersers can, therefore, travel across the landscape searching for actually the best habitat patches to occupy, establish temporal residence and breed successfuly there. Such a nomadic existence gives the best opportunity to satisfy all life requirements of the species in a proper time, but requires a high fecundity of animals and a short generation time. Both these characteristics are quite common in most of small mammal species. It also requires a high level of dispersal and abilities of dispersers to travel a relatively long distances. Recent literature gives some good data indicating unexpectadly high dispersal abilities of many small mammal species (e.g. Andrzejewski and Babińska-Werka 1986, Liro and Szacki 1987, Wegner and Merriam 1990, Szacki and Liro 1991, Kozakiewicz et al., in press).

Another possible way to satisfy all life requirements in a heterogeneous landscapes is to enlarge as much as possible the range of individual movements. As is described above, there are some data in the literature suggesting that individuals of many small mammal species can make exploratory excursions outside the habitat patches they actually occupy and visit several neighbouring patches of habitat (Fig. 7). This kind of spatial activity also gives the opportunity to use a wide array of resources offered in all visited patches of habitat, available within the whole range of movements of individual. Although this kind of spatial activity could be expected rather in animals larger than small mammals, results of homing experiments already described above seem to indicate that such a possibility might be realized also in small mammal populations. It can be supposed that it might depend on the way of spatial arrangement of a suitable patches of habitat (especially distances between habitat patches must be easily passable for animals).

Kozakiewicz et al. (in press) studied movements of Bank voles in homogeneous and heterogeneous environments by using a marked bait. The results obtained give clear evidence that distances travelled by Bank voles are significantly longer in heterogeneous habitats compared to homogeneous ones (Table 5). Extremely long distances travelled by Striped-field mice and Bank voles were recorded in a very heterogeneous suburban mosaics by Liro and Szacki (1987) and Szacki and Liro (1990). Also Merriam (1990) and Wegner and Merriam (1990) give evidences of extremely long distances moved by White-footed mice in mosaic farm landscape.

Table 5. Mean distance ( $\pm S E$ ) and longest recorded distances moved by Bank voles Clthrionomys glareolus in homogeneous (A) and heterogeneous (B) habitats. After Kozakiewicz et al. (in press).

\begin{tabular}{lcc}
\hline Distance (m) & A & B \\
\hline Mean \pm SE & $135 \pm 116$ & $243 \pm 133$ \\
Longest recorded & 440 & 480 \\
\hline
\end{tabular}

Table 6. Mean density of intestinal parasite species in the "Woodlot" and large "Forest" Bank vole Clethrionomys glareolus populations, and per cent of voles infected. $*-p<0.05$ ( $t$-test) After Kozakiewicz (1991), modified.

\begin{tabular}{lcc}
\hline & Woodlot & Forest \\
\hline Mean density & $3.9 \pm 3.4^{*}$ & $\begin{array}{c}2.1 \pm 1.9^{*} \\
\text { \%of voles infected }\end{array}$ \\
\hline
\end{tabular}


Kozakiewicz et al. (1992) studied seasonal dynamics of small mammal community of a lake shore habitat surrounded by mosaic farm landscape. The studied community showed a low number of permanent species compared to the number of temporal visitors. This was reflected by deep seasonal changes of the species composition due to seasonal changes of the quality of both shore and adjacent habitats. All these data suggest that increased movement range (both in short-time periods and in long-time and large-spatial scales) might be a common behavioural response of small mammals to increased habitat heterogeneity.

Considering annual population cycles of numerous small mammal species, especially in temperate and subarctic zones, seasonal variation in their habitat requirements can be easily observed. It must be pointed out, however, that in some seasons or in some stages of a life cycle, species' needs might be very special and filling these needs might be of crucial importance for population survival. Habitats they can fill such a needs may be, therefore, considered "key habitats" for population persistence. For example, many amphibian species need water bodies or wet habitats to breed, numerous bird species have a very special requirements for nesting habitats, etc.

It can be suggested that in temperate and subarctic zones, winter habitats and those in which animals can start early spring breeding, are of special importance for small mammals. The special significance of winter habitats for population survival of many small mammal species as well as special winter habitat

Fig. 10. The schematic picture of year-round cycle of Levins' (1970) metapopulation (A) and nomadic-type metapopulation (B). Dark spots - patches of habitat presently occupied, white spots - patches of habitat not occupied at present, shaded areas - terrains explored by animals from habitat patches, arrows show possible directions of animals' movements. After Kozakiewicz el al. (in press).

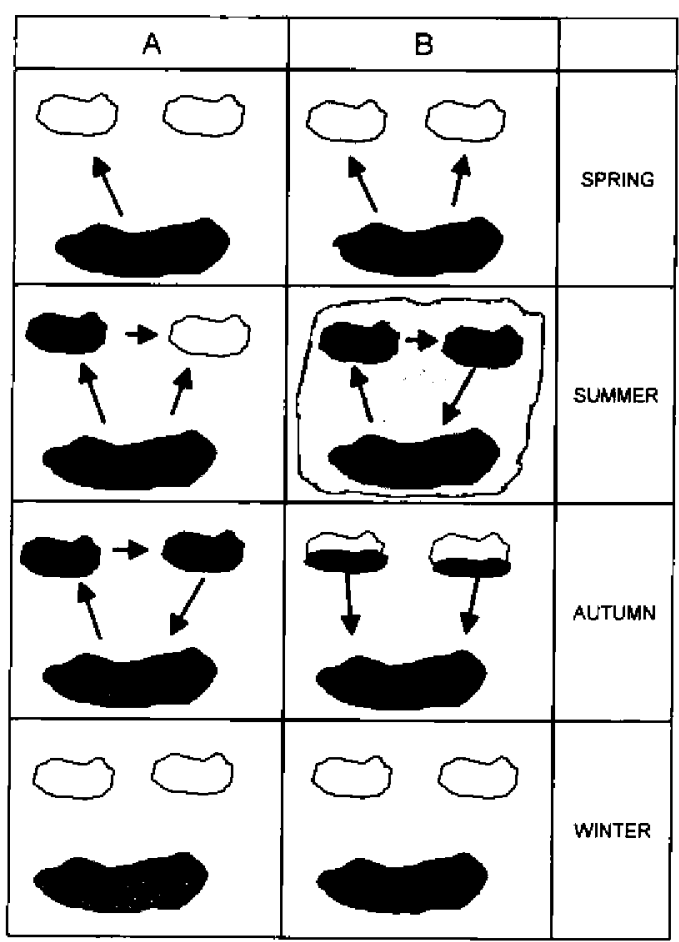


requirements of the species were widely discussed in the literature (e.g. Kalela et al. 1961, 1971, Kaikusalo 1972, Tast and Kaikusalo 1976, and many others).

In mosaic landscapes patches of such key habitats can be spatialy scattered, producing therefore better chances for highly mobile animals to find them in a proper time, establish temporal residence and survive. A round-year cycle of such nomadic Bank vole metapopulation was described by Kozakiewicz et al. (in press; Fig. 10). In spring voles disperse from the best patches of overwintering habitats, colonize empty patches and start to breed there. During the reproductive season animals move frequently among occupied patches; a large portion of individuals use more than one habitat patch. In autumn a large number of highly mobile animals choose the best habitats for wintering, thus decreasing the probability of local winter extinctions.

It can be, therefore, concluded that increased mobility of individuals might be a good strategy for population survival in a mosaic, heterogeneous landscapes. It can be also suggested that specialist species might be expected to be more mobile than generalists, since their needs are more precisely defined and less of habitat patches are acceptable for them.

According to Wegner and Heinen (1991), individuals of Eastern chipmunk - a woodland specialist species - do not venture into agricultural fields, being strongly restricted to patchily distributed wooded areas in a mosaic farm landscapes. Despite greatly extended range through network of fencerows, chipmunks are not able to travel long distances across the landscape and select actually the best patches of habitat. In contrast to the "high spatial activity" strategy discussed above, this species seems to develope and realize "dormancy" tactics, being inactive during the whole winter. This "strategy of waiting for better conditions", although common in small mammals inhabiting extremely changeable habitats (e.g. deserts, high mountins, etc.), seems to be rarely realized in heterogeneous landscapes.

\section{Effect of habitat isolation on selected interspecific interactions}

\subsection{Habitat barriers and distribution of species}

Interspecific interactions among small mammals in heterogeneous environments are discussed widely in the literature. Here I point out briefly only the possible role, which habitat barriers can play in shaping the distribution of a species in fragmented landscapes.

It seems that, similarly to different individuals within the population, also different species within the community can undergo selective effects of habitat barriers. This may account in part for a distinct character of animal communities in various patches of the habitat. This may be illustrated by the already quoted removal experiment and the subsequent recolonization by rodents of the isolated woodlot surrounded by a meadow (barrier) and a large continuous forest plot (Kozakiewicz and Jurasińska 1989). This meadow created a barrier to Bank voles, 

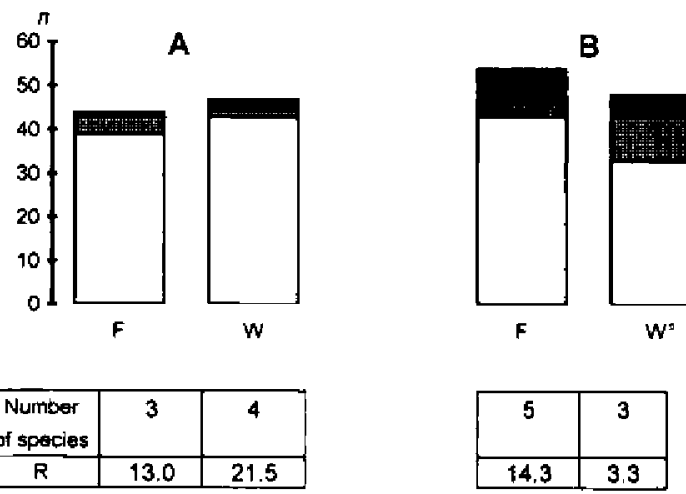

\begin{tabular}{|c|c|c|}
\hline $\begin{array}{c}\text { Number } \\
\text { of species }\end{array}$ & 3 & 4 \\
\hline$R$ & 13.0 & 21.5 \\
\hline
\end{tabular}

Fig. 11. Species composition and numbers of individuals in a small mammal community occupying a large forest (F) and a small woodlot (W) prior to a removal experiment (A) and in the fourth week of recolonization (B). $R$ - ratio of the number of Bank voles to the number of Yellow-necked mice. After Kozakjewicz and Jurasifiska (1989).

but it did not limit so much movements of other rodents, e.g. Yellow-necked mice. As a result, the proportion of different species in the community after recolonization in the isolated woodlot differed from that in the nonisolated forest plot, while did not prior to a removal experiment (Fig. 11).

The distribution of different species across the fragmented landscape can be affected by such "filter" effects of habitat barriers. From one side it may depend on species' habitat requirement's and their abilities to move, and from another side - on spatial composition of the landscape.

A good example of two different species characterized by two different spatial strategies but coexisting in the fragmented landscape in central Belgium has been given by Bauchau and Le Boulengé (1991). The Bank vole has been recognized by authors as a species characterized by strict habitat requirements and relatively low dispersal potential, while Wood mouse Apodemus sylvaticus has been shown as an example of a habitat generalist and opportunist, exhibiting high dispersal rates. Bank voles were not observed outside woody habitats. Those woodlots where the Bank voles were present were large and less isolated ones, while Wood mice occupied nearly all plots being analysed, and moved frequently between habitat patches (Bauchau and Le Boulengé 1991).

4.2. Host-parasite interactions, an example: intestinal helminths in Bank vole

Spatial composition of the landscape, affecting the distribution of many single species, can also influence interactions among them. Among papers concerning parasites of small mammals there are some dealing with the role which spatial distribution of hosts can play to influence their parasite fauna (Kisielewska 1970, Haukiasalmi et al. 1987).

It seems, that host-parasite interactions are far more specific than any other ones, because of a very close relationships among species and a very high level of 
dependence of parasites on their hosts' populations. On the other hand, there is a large number of factors which can influence this relationship by affecting the probability of being infected with a given parasite species. All these factors can be influenced by heterogeneity of habitats. Therefore, in fragmented landscapes, the isolation of habitat patches (influencing spatial distribution of hosts), and habitat barriers (inhibiting hosts' inter-patch movements, including the intermediate hosts), can affect in this indirect way the host-parasite interactions.

An example has been given by Kozakiewicz (1991), who compared an intestinal helminth fauna of Bank voles inhabiting a large, continuous forest and a small, isolated woodlot. It has been found, that voles inhabiting isolated woodlot were infected with much smaller number of parasite species, comparing to those inhabiting a large forest (Fig. 12). However, the mean density (the number of parasites per host specimen) as well as per cent of voles infected, were higher in

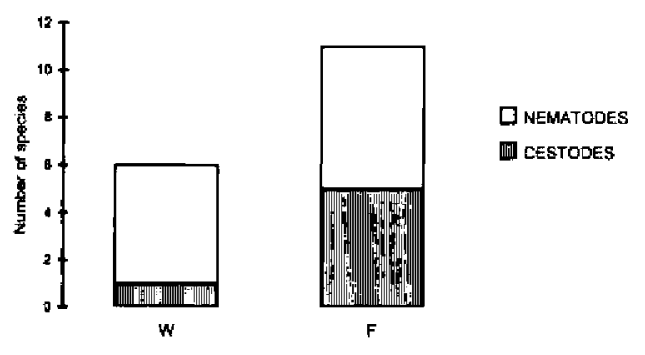

Fig. 12. Taxonomical structure of the helminth groupings in the woodlot (W) and large forest (F) Bank vole Clethrionomys glareolus populations. Afer Kozakiewiez (1991), modified.

"woodlot" group of Bank voles compared to "forest" one (Table 6). The voles inhabiting isolated woodlots were infected mainly with helminth species which are characterized by a simple life cycle without an intermediate host. The voles caught in a large forest were infected with so-called biohelminths as well (their life cycle includes at least one intermediate host). The high "saturation" of the patch habitat with helminth larvae and eggs, the lack of some intermediate hosts, the frequent contacts among vole individuals, the inhibition of inter-patch movements and the possible local extinctions were suggested and discussed as possible reasons for a different character of intestinal helminth fauna of Bank voles inhabiting isolated woodlot (Kozakiewicz 1991).

\section{Summary and conclusions}

1. Spatial heterogeneity of landscapes and their changeability in time must be recognized as fundamental features of a natural situation. Despite natural disturbances, the development of agriculture and man-made processes of land clearing lead to the division of natural, previously large areas of vegetation, like forests, into small discrete patches. For many woodland species (including small mammals) this means the division of their populations into several small 
subpopulations occupying suitable patches of habitat. These patches can be situated in different positions in the landscape, have different vegetation structure and vary in their shape, size and degree of isolation. Landscape variability in space and time produces a "dynamic mosaic" of habitats and offers to animal populations living there a wide range of different conditions.

2. The small, patch populations are interconnected by occasional movements of individuals between them (non-continuous distribution). The group of such interconnected subpopulations can be spatially and functionally structured as a demographic unit, called "metapopulation". The dynamics of a whole metapopulation are built up as a result of within-patch demographic processes and between-patch movements of individuals. Patch populations can seasonally become so small that local extinctions may occur. Movements of individuals between habitat patches and recolonization processes are, therefore, critical to support the existence of the species in fragmented landscapes.

3. Within-patch ecological processes are influenced strongly by small size of each subpopulation and the isolation of the habitat. Specific social and spatial structure of patch populations and also limitation of emigration processes seem to be possible mechanisms reducing the probability of local extinctions.

4. The "connectivity" is the parameter which measures inter-patch processes. It depends both on movement patterns of animals and on the landscape composition (barriers/corridors).

Habitat barriers can put boundaries on movements of a single individuals (individual home range level), they can also limit (inhibit) processes of recolonization of empty habitat patches (within metapopulation level), or they can be effective enough to stop the gene flow between metapopulations (evolutionary deme level).

The inter-patch connectivity can be modified by barrier "filtering" effect. Habitat barriers may act as "filters" which stop some individuals and allow others to pass through, according to their abilities to move. Such "filters" can play an important role in structuring small subpopulations. By "filtering out" different species, habitat barriers can also play an important role in affecting species distribution across fragmented landscapes.

The inter-patch connectivity also can be modified by specific movement patterns of some small mammals which are able to make temporal exploratory excursions outside habitat patches. These exploratory movements of animals between patches can be very important for gene flow within metapopulation in a longer time.

5. Patchy distribution of animals prevents random breeding but also does not cause genetic isolation of each subpopulation. The small size of discrete subpopulations, which temporarily go through a genetic bottleneck effect, and occasional migration of individuals between subpopulations, can induce increased, long term genetic variability of the whole metapopulation. 
6. Landscape heterogeneity and habitat fragmentation, affecting the distribution of many species, can also affect interspecific interactions, host parasite interactions in this number.

7. Ecological processes, which are going on among patchily distributed subpopulations, make the metapopulation a dynamic, functional unit. Metapopulation, therefore, is not a simple sum of all patch populations, but it is functionally fused by inter-patch processes. Connectivity has always to be considered as the dynamic parameter, which measures processes and their effects in the spatial scale of the whole landscape and in long term scale. Equilibrium theory of island biogeography has no application in metapopulation studies, because of much wider range of possibilities of inter-patch connectivity, compared to real islands. The way in which animals react to this landscape variability in space and time, depends on species-specific characteristics.

8. There is a kind of dynamics of species' needs and resource supply in heterogeneous landscapes. For each species the temporal distribution of activity in space should reflect the interactions between the temporal dynamics of the species' needs and spatio-temporal dynamics of resources. There are habitat types of crucial significance for population survival, called "key habitats" here.

Increased mobility of individuals seems to be the best strategy for survival in heterogeneous landscapes. Highly mobile individuals seem to have better chances to find in a proper time spatialy scattered patches of habitats, establish temporal residence, survive and breed successfuly there.

Acknowledgements: I am grateful to Dr G. Merriam, Professor of Biology (Carleton University, Otlawa) for helpful discussions, constructive comments, and kind correction of the English manuscript. This work was granted by Research Program 04.10.

\section{References}

Andrzejewski $R$. and Babifiska-Werka J. 1986. Bank vole populations: are their densities really high and individual home ranges small? Acta theriol. 31: $407-420$.

Apeldoorn R. van, Oostenhrink W. T., Winden A. van and Zee S. van der 1992. Elfects of habitat fragmentation on the bank vole, Clethrionomys glareolus, in an agricultural landscapes. Oikos 65 : $265-274$.

Bauchau V. 1987. Eflect of habitat patchiness on ecological and genetic structure of woodland rodent population. [In: Report of the First European Meeting: "The Rodent and Its Environment"]. Mammalia 51: $468-469$.

Bauchau V. 1988. Non-metrical variation in wild mammals: a bibliography. Mammal Rev. 18: $195-200$.

Bauchau V. and Le Boulenge E. 1991. Population biology of woodland rodents in a patchy landscape. [In: Le Rongeur et l'Espace. M. Le Berre and L. Le Guelte, eds]. R. Chabeud, Paris: 275 - 283.

Bakowski C. and Kozakiewicz M. 1988. The effect of forest road on bank vole and yellow-necked mouse populations. Acta theriol. 33: 345-353.

Blake J. G. and Karr J. R. 1984. Species composition of bird cammunities and the conservation benefit of large versus small forests. Biol. Conserv. 30: 173-187.

Boecklen W. J. and Bell C. W. 1987. Consequences of faunal collapse and genetic drift for the design of nature reserves. [In: Nature conservation: the role of remnants of native vegetation. D. A. 
Saunders, G. W. Arnold, A. A. Burbridge and A. J. M. Hopkins, eds]. Surrey Beatty and Sons, Chipping Norton, Australia: 141 - 149.

Boer P. J. den 1968. Spreading of risk and stabilization of animal numbers. Acta biotheoret. 18: $165-194$.

Boorman S. A. and Levitt P. R. 1973. Group selection on the boundary of a stable population. Theor. Popul. Biol. 4: 85- 128.

Bujalska G. 1970. Reproduction stabilizing elements in an island population of Clethrionomys glareolus (Schreber, 1780). Acta theriol. 15: 382 - 412.

Bujalska G. 1973. The role of spacing behaviour among females in the regulation of reproduction in the bank vole. J. Reprod. Fert., Suppl. 19: 463 - 472.

Burgess R. L. and Sharpe D. M. (eds) 1981. Forest island dynamics in man dominated landscapes. Springer Verlag, New York, Heidelberg, Berlin, Ecological Studies 41: 1-310.

Chepko-Sade B. D., Shields W. M., Berger J., Tang-Halpin Z, Jones W. T., Rogers L. L., Rood J. P. and Siniths A. T. 1987. The effects of dispersal and social structure on effective population size. [In: Mamma]ian dispersal patterns. The effects of social structure on population genetics. B. D. Chepko-Sade and Z. Tang-Halpin, eds]. The University of Chicago Press, Chicago, London: $287-321$.

Corbet G. B. 1963. An isolaled population of the bank vole Clethrionomys glareolus with aberrant dental pattern. Proc. Zool. Soc. Lond. 140: 316 - 319.

Diamond J. M. 1976. Island biogeography and conservation: strategy and limitations. Science 193: $1027-1029$.

Dobrowolski K., Banach A., Kozakiewicz A. and Kozakiewicz M. (in press): Effect of habitat barriers on animal populations and communities in heterogenous landscapes. [In: Biotic diversity in agroecosystems. M. Pimentel and G. Paoletti, eds]. CRC Press, Boca Raton, Fl, USA.

Fahrig L. and Merriam G. 1985. Habitat patch connectivity and population survival. Ecology 66: $1762-1768$.

Forman R. T. T. 1981. Interaction among landscape elements: a core of landscape ecology. Proc. Int. Congr. Neth. Soc. Landscape Ecol., Veldhoven, Pudoc, Wageningen, the Netherlands: $35-48$.

Forman R. T. T. and Godron M. 1986. Landscape ecology. John Wiley \& Sons, Inc., New York, Chichester, Brisbane, Toronto, Singapore: $1-619$.

Gilpin M. E. 1987. Spatial structure and population vulnerability. [In: Viable populations for conservation. M. E. Soule, ed]. Cambridge Univ. Press. Cambridge, NY, New Rochelte, Melbourne, Sydney: $125-140$.

Gliwiez J. 1980. Island populations of rodents: their organization and functioning. Biol. Rev. 55: $109-138$.

Gliwicz J. 1989. Individuals and populations of the bank vole in optimal, suboplimal and insular habitats. J. Anim. Ecol. 58: 237 - 247.

Gliwicz J. 1990. What can be learnt about the role of "forest islands" in a landscape from rodent investigations. Wiad. Ekol, 36: 21-35. [In Polish with English summary]

Gliwicz J. 1992. Patterns of dispersal in non-cyclic populations of small rodents. [In: Animal dispersal. Small mammals as a model. N. Ch. Stenseth and W. Z. Lidicker, Jr, eds]. Chapman \& Hall, London, New York, Tokyo, Melbourne: 147 - 159.

Gottfried B. M. 1979. Small mammal populations in woodlot islands. Am. Midl. Nat. 102: 105 - 112.

Gottfried B. M. 1982. A seasonal analysis of small mammal populations of woodlot islands. Can. J. Zool. 60: $1660-1664$.

Hanski I. and Gilpin M. 1991. Metapopulation dynamic: brief history and conceptual domain. Biol. J. Linn. Soc. 42: 3- 16 .

Hansson L. 1977a. Spatial dynamics of field voles Microtus agrestis in heterogenous landscapes. Oikos 33: 539 - 544

Hansson L. 1977b. Landscape ecology and stability of populations. Landscape Plann. 4: 85 - 93. 
Hansson L. 1981. Immigration to human habitations by south Swedish small mammals. Z. angew. Zool. 68: $339-355$.

Hansson L. 1987. Dispersal routes of small mammals at an abandoned field in central Sweden. Holaretic Ecol. 10: 154 - 159.

Hansson L. 1988. Dispersa] and patch connectivity as species-specific characteristics. [In: Connectivity in Landscape Ecology. Proc. 2nd Int. Sem. LALE. K. F. Schreiber, ed]. Munstersche Geographische Arbeiten 29, Munster: 111 - 113.

Harris L. D. 1984. The fragmented forest; island biogeography theory and the preservation of biotic diversity. The University of Chicago Press, Chicago, London: $1-211$.

Haukiasalmi V., Henttonen H. and Tenora F. 1987. Parasitism by helminths in the grey-sided vole (Clethrionomys rufocanus) in northern Finland: influence of density, habitat and sex of the host. J. Wildl. Dis. 23: $233-241$.

Henderson M. T., Merriam G. and Wegner J. 1985. Patchy environments and species survival: chipmunks in an agricultural mosaic. Biol. Conserv. 31: 95- 105.

Janzen D. H. 1983. No park is an island: increase in interference from outside as park size decreases. Oikos 41: $402-410$.

Kaikusako A. 1972. Population turnover and wintering of the bank vole, Clethrionomys glareolus (Schreb.), in southern and central Finland. Ann. zool. Fenn. 9: 219-224.

Kalela O., Kilpelainen L., Kopponen T. and Tast J. 1971. Seasonal differences in habitats of the Norwegian lemming, Lemmus lemmus (L.), in 1959 and 1960 at Kilpisjarvi, Finnish Lapland. Ann. Acad. Sci. Fenn. Ser. A 178: 1- 22.

Kalela O., Kopponen T., Lind E. A., Skaren V. and Tast J. 1961. Seasonal change of habitat in the Norwegian lemming, Lemmus lemmus L. Ann. Acad. Sci. Fenn. Ser. A 55: 1 - 72.

Kisielewska K. 1970. Ecological organization of intestinal helminth groupings in Clethrionomys glareolus (Schreb.) (Rodentio). An attempt at introduction of helminths of C. glareolus from the Bialowieza National Park into a island of the Beldany Lake (Mazurian Lakeland). Acta Parasit. Pol. 18: 149 - 162 .

Kozakiewicz A., Kozakiewicz M. and Choszczewska B. 1992. Small mammal communities of the nature reserve "Luknajno Lake" coastal zone. Parki Nar. i Rezerwaty Przyr. 11: 121 - 130.

Kozakiewicz M. 1983. Environmental and ecological effects of artificial division of the population area. [In: Environment and population: problems of adaptation. J. B. Calhoun, ed]. Praeger Publ., New York: $22-23$.

Kozakiewicz M. 1985. The role of habilat isolation in formation of structure and dynamics of the bank vole population. Acta theriol. 30: $193-209$.

Kozakiewicz M. 1991. Intestinal helminth groupings in open and patch bank vole population - the role of habitat isolation. Bull. Acad. Pol. Sci. Cl. II 39: 379-385.

Kozakiewicz M. and Konopka J. 1991. Effect of habitat isolation on epigenetic divergence of the bank vole population. Acta theriol. 36: $363-367$.

Kozakiewicz M. and Jurasinska E. 1989. The role of habitat barriers in woodlot recolonization by small mammals. Holarctic Ecol. 12: 106-111.

Kozakiewicz M., Kozakiewicz A., Lukowski A. and Gortat T. (in press). Use of space by bank voles (Clethrionomys glareolus) in a Polish farm landscape. Landscape Ecol.

Kozakiewicz M. and Szacki J. 1987. Small mammals of jsolated habitats - islands on the mainland or jsland populations only? Wiad. Ekol. 33: 31 - 45. [In Polish with English summary]

Kozel R. M. and Fleharty E. D. 1979. Movements of rodents across roads. SWest. Nat. 24: $239-248$.

Lefkovitch L. P. and Fahrig L. 1985. Spatial characteristics of habitat patches and population survival. Ecol. Model. 30: 297 - 308 .

Levins R. 1970. Extinction. [In: Some mathematical questions in biology. Lectures on mathematics in the life sciences]. American Mathematical Society, Provenience. R.I., vol. 2: 75-108.

Liro A. and Szackj J. 1987. Movements of field mice Apodemus agrarius (Pallas) in a suburban mosaic of habitats. Oecologia 74: $438-440$. 
Lovejoy T. E. and Oren D. C. 1981. The minimum critical size of ecosystem. [In: Forest island dynamics in man-dominated landscapes. R. L. Burgess and D. M. Sharpe, eds]. Springer Verlag, New York, Heidelberg, Berlin, Ecological Studies 41: 7 - 12.

MacArthur R. H. and Wilson E. O. 1963. An equilibrium theory of insular biogeography, Evolution 17: $373-387$.

MacArthur R. H. and Wilson E. O. 1967. The theory of island biogeography. Princeton Univ. Press., Princeton, New Jersey: 1 - 203.

Mader H. J. 1984. Animal habitat isolation by roads and agricultural fields. Biol. Conserv. 29: 81 - 96.

Margules C. R. and Stein J. L. 1989. Patterns and distributions of species and the selections of nature reserves: an example from Eucalyptus forests in south-eastern New South Wales. Biol. Conserv. 50: $219-238$.

Markowski J. and Sikorski M. D. 1987. Use of non-metrical traits in population study. Prz. Zool. 31: 7 - 23. [In Polish with English summary]

Merriam G. 1984. Connectivity: a fundamental ecological characteristic of landscape pattern. IIn: Proc. First Internat. Sem. on Methodology in Landscape Ecological Research and Planning. J. Brandt and P. Agger, eds]. IALE, Roskilde University, Roskilde: 5 - 15.

Merriam G. 1988. Landscape dynamics in farmland. Tree 3: $16-20$.

Merriam G. 1990. Ecological processes in the time and space of farmland mosaics. [In: Changing landscape: an ecological perspective. I. S. Zonnefeld and R. T. T. Forman, eds]. Springer Verlag, New York, Heidelberg, Berlin: $121-133$.

Merriam G. 1991. Corridors and connectivity: animal populations in heterogenous environments. [In: Nature conservation 2: the role of corridors. D. Saunders, ed]. Surrey Beatty Pty. Chipping Norton, Australia: $133-142$.

Merriam G., Kozakiewicz M., Tsuchiya E. and Hawley K. 1989. Barriers as boundaries for metapopulations and demes of Peromyscus leucopus in farm landscapes. Landscape Ecol. 2: 227 235.

Middleton J. and Merriam G. 1981. Woodland mice in a farmland mosaic. J. Appl. Ecol, 18: 703 - 710.

Middleton J. and Merriam G. 1983. Distribution of woodland species in farmland woods. J. Appl. Ecol. 20: $625-644$.

Opdam P. 1988. Populations in fragmented landscape. [In: Connectivity in Landscape Ecology. Proc. of the 2nd Inter. Sem. IALE]. Munsterche Geograpische Arbeiten 29, Munster: 75 - 77.

Oxley D. J., Fenton M. B. and Carmody G. R. 1974. The effects of roads on populations of small manmals. J. Appl. Ecol. 11: 51 - 59 .

Reddingius J. and den Boer P. J. 1970. Simulation experiments illustrating stahilization of animal numbers by spreading of risk. Oecologia $5: 240-284$.

Roff D. A. 1974a. Spatial heterogeneity and the persistence of populations. Oecologia 15: $245-258$.

Roff D. A. 1974b. The analysis of a population model demonstrating the importance of dispersal in a helerogenous environment. Oecologia 15: $259-275$.

Roff D. A. 1975. Population stability and the evolution of dispersal in a heterogenous environment. Oecologia 19: 217 - 237.

Saunders D. A., Arnold G. W., Burbidge A. A. and Hopkins A. J. M. (eds) 1987. Nature conservation: the role of remnants of native vegetation. Surrey Beatty and Sons, Chipping Norton, Australia: $1-410$.

Saunders D. A., Hobbs R. J. and Margules C. R. 1991. Biological consequences of ecosystem fragmentation: a review. Conserv. Biol, 5: $18-31$.

Schreiber R. K. and Graves J. H. 1977. Powerline corridors as possible barriers to the movements of small mammais. Am. Midl. Natur. 97: 504 - 508.

Sikorski M. 1982. Non-metrical divergence of isolated populations of Apodemus agrarius in urban areas. Acta theriol. 27: $169-180$.

Sikorski M. and Bernshtein A. D. 1984. Geographical and intrapopulation divergence in Clethrionomys glareolus. Acta theriol. 29: $219-230$. 
Simberloff D. S. 1976. Species turnover and equilibrium island biogeography. Science 194: $572-578$.

Simberlaft D. S. and Abele L. G. 1976a. Island biogeography and conservation: strategy and limitations. Science 193: 1032.

Simberloff D. S. and Abcle L. G. 1976b. Island biogeography theory and conservation practice. Science 191: $285-286$.

Smith A. T. and Vrieze J. 1979. Population strueture of Everglades rodents: responses to a patchy environment. J. Mamma]. 60: 778 - 797.

Stenseth N. Ch. and Lidicker W. Z., Jr (eds). 1992. Animal dispersal. Small mammals as a model. Chapman and Hall, London, New York, Tokyo, Melbourne: $1-365$.

Stickel L. F. and Warbach O. 1960. Small mammal populations of a Maryland woodlot 1949-1954. Ecology 41: 269 - 286.

Swihart R. K. and Slade N. A. 1984. Road crossing in Sigmodon hispidus and Microtus ochrogaster. J. Mammal. 65: $357-360$.

Szacki J. 1987. Ecological corridors as a factor determining the structure and organization of bank vole population. Acta theriol. 32: $31-44$.

Szacki J. and Liro A. 1991. Movements of small mammals in the heterogenous landscape. Landscape Ecol. 5: 219 - 224 .

Tast J. and Kaikusalo A. 1976. Winter breeding of the root vole, Microtus oeconomus, in 1972/1973 at Kilpigjarvi, Finnish Lapland. Ann. zool. Fenn. 13: $174-178$.

Terborgh J. 1976. Is]and biogeography and conservation: strategy and limitations. Science 193: 1029 - 1030 .

Verboom J., Schotman A., Opdam P. and Metz J. A. J. 1991. European nuthatch metapopulations in a fragmented agricultural landscapes. Oikos 61: $149-156$.

Verboom J. and Lankester K. 1991. Linking local and regional dynamics in slochastic metapopulation models. Biol. J. Linn. Soc. 42: $39-55$.

Wegner J. and Heinen K. 1991. Strategies for survival: white-footed mice and eastern chipmunks in an agricultural landscape. Proc. LALE World Congress, Ottawa, Canada: 90.

Wegner J. F. and Merriam G. 1979. Movements by birds and small mammals between wood and adjoining farmland habitats. J. Appl. Ecol. 16: $349-357$.

Wegner $J$. and Merriam G. 1990 . Use of spatial elements in a farmland mosaic by a woodland rodent. Biol. Conserv. 54: $236-276$.

Whitcomb R. F., Lynch J. F., Opler P. A. and Robbins C. S. 1976. Island biogeography and conservation: strategy and limitations. Science 193: $1030-1032$.

Wiens J. A. 1976. Population responses to patchy environments. Ann. Rev. Ecol. Syst. 7: $81-120$.

Wiens J. A. 1989. The ecology of bird communities. vol. II. Processes and variations. Cambridge Univ. Press. Cambridge, N.Y., Port Chester, Melbourne, Sydney: 1 - 316.

Wilkins K. T. 1982. Highways as barriers to rodent dispersal. SWest. Nat. 37: 459-460.

Windberg L. A. and Keith L. B. 1978. Snow shoe hare populations in woodlot habitat. Can. J. Zool. 56: $1071-1080$.

Wolton R. J. and Flowerdew J. R. 1985. Spatial distribution and movements of wood mice, yellow-necked mice and bank voles. Symp. Zool. Soc. Lond. 55: 249 - 275.

Zejda J. 1966. Litter size in Clethrionomys glareolus (Schreber, 1780). Zool. Listy 15: 193 - 206.

Zimmerman B. L. and Bierregaard R. O. 1986. Kevelance of the equilibrium theory of island biogeography and specieg-area relations to conservation with a case from Amazonia. J. Biogeogr. 13: $133-143$.

Received 4 March 1991, revised 4 February 1993, accepted 12 March 1993. 